\title{
Comparative Evaluation of Three-phase Voltage and Current Source Inverter in Renewable Energy System
}

\author{
S Y Chong ${ }^{1}$, S A Azmi ${ }^{1,2, *}$ J H Leong ${ }^{1,2}$ \\ ${ }^{1}$ School of Electrical System Engineering, Universiti Malaysia Perlis, Malaysia \\ ${ }^{2}$ Centre of Excellence for Renewable Energy (CERE), Universiti Malaysia Perlis, Malaysia
}

Received August 15, 2019; Revised December 19, 2019; Accepted December 24, 2019

Copyright@2019 by authors, all rights reserved. Authors agree that this article remains permanently open access under the terms of the Creative Commons Attribution License 4.0 International License

\begin{abstract}
In the renewable energy power generation system, voltage source inverters (VSIs) are commonly used due to its stable operation, high efficiency and low cost. However, a dc-dc boost converter is necessary for VSI to operate which has increased the system complexity. Thus, current source inverters (CSIs) has become an alternative of VSI due to its ability of voltage boosting and can provide a better output waveform. This paper presents a comparative evaluation of VSI and CSI focusing on topological circuits and basic operational parameters of these inverters. The performances of VSI and CSI are analyzed in MATLAB/Simulink focusing on two operational characteristics which are modulation index, $m_{a}$ and switching frequency, $f_{s w}$. The performances of VSI and CSI are dependent on the modulation index, increasing $m_{a}$ increase the inverter efficiency. In term of switching frequency, it does not affect much on the efficiency of inverters, yet a normalized switching frequency of odd multiple of three provides better fundamental output and harmonic minimization. Furthermore, CSI presents its voltage boosting capability which can boost $6-27 \%$ within $m_{a}$ of $0.05-1.0$ and using the same modulation technique, VSI and CSI have present duality relationship in term of output voltage and current wave shapes.
\end{abstract}

Keywords Voltage Source Inverter, Current Source Inverter, PWM, Inverter Duality, Modulation Technique, Switching Frequency

\section{Introduction}

In recent year, renewable energy source is rising due to increasing concern on environment pollutions and potential scarcity of fossil fuels. Thus, renewable energy has become a growing concern in power generation and distribution system since it is clean and friendly to environment.
In renewable energy power generation and distribution system, an inverter plays an important role to convert the dc input to ac output with a fixed magnitude and frequency [1]. Inverter can be classified as voltage source inverter (VSI) and current source inverter (CSI) based on their input source. Recently, VSI is most commonly used due to its operation stability, ease of control, high efficiency and low cost [2-4]. However, VSI always required a dc-dc boost converter for boosting and regulating its input voltage [3,4]. This increase the circuit complexity and power losses for overall system. As for CSI, it has advantages features such as provide better output voltage and current waveform quality compared to VSI [2]. Furthermore, CSI can implicit voltage boosting capability through its dc-link inductor which acts same function as a dc-dc boost converter $[2,3,11]$. This feature has led CSI to become an alternative of VSI with a dc-dc boost converter.

Since both inverters have their own advantages and disadvantages, comparative analysis seems to be important in order to select suitable topology for the required application. There are several comparative analyses has been investigated in term of power losses and system efficiency [2,5-7]. In [5], a VSI and a CSI with an intermediate step-down converter are implemented to a low-power induction motor which its power is below $1 \mathrm{~kW}$. Both inverters are compared in term of motor efficiency, insulation stress and common voltage. The result shows that CSI can provide a less distortion motor output voltage and current, has a satisfied performance for insulation stress and common voltage. From overall result, the efficiency of CSI is comparable to that of VSI for a low-power induction motor. For medium voltage application [6], three types of inverters which are CSI with active front-end, CSI with 18-p thyristor rectifier and VSI with 12-p diode rectifier are compared based on conduction losses, switching losses and system efficiency. The result in [6] shows that both CSIs have a lower efficiency compared to VSI due to higher conduction losses in 
snubber and dc-link inductor. For high power application, [7] presents a comparative analysis of several types of VSIs and CSIs. In [7], the result shows that the efficiency of VSIs and CSIs are competitive for nonregenerative low dynamic applications while in regenerative application, VSIs can achieves higher efficiency than CSIs. In addition, a load-commutated CSI is preferred for very high power applications due to its high reliability and efficiency [7].

Furthermore, the comparative analyses from low to high switching frequency applications also establish in [2], which state VSI has lower total semiconductor power losses at low switching frequency while CSI has lower total semiconductor power losses at high switching frequency. From these previous researches, they indicate that the selection of inverter topology should be always based on the industrial requirement.

Although VSI and CSI have different features, they also present a duality relationship. In [8], the authors present the duality of VSI and CSI output equivalent circuits through mathematical theory and calculation. In addition, due to the duality relationship of VSI and CSI, the same modulation techniques can be implemented into both inverters [8].

The modulation technique is one of the important criteria that affect the efficiency of inverters. One of the most common modulation techniques is the sinusoidal pulse width modulation (SPWM) technique. This modulation technique provides an adjustable output voltage or current and acts as a harmonic elimination [9-13]. This paper presents a comparative evaluation of VSI and CSI based on the operational characteristics of modulation index, $m_{a}$ and switching frequency, $f_{s w}$. The open-loop performance of both inverters is investigated in term of fundamental output and THD in MATLAB/Simulink.

\section{System Configuration}

The basic topologies of VSI and CSI are shown in figure 1. VSI consists of six switches (IGBTs) which can be turned on and off to produce a pulse-width modulation (PWM) voltage signal for regulating system switching frequency and output fundamental frequency. An uncontrolled diode is connected in anti-parallel with each switch to provide a current path for inductive loads [1]. A dc-link capacitor is connected parallel to dc input voltage source. This dc-link capacitor functions as filtering dc input, regulating dc-link voltage ripple and provide energy storage for the system [2-4]. A simple LC filter is used for VSI for harmonic elimination.

Meanwhile in CSI, there are six switches which each connected with an uncontrolled diode in series. These diode functions as reverse current voltage blockage for the IGBTs. For CSI, its passive component in dc-link side is a dc-link inductor. This dc-link inductor implicit voltage boosting characteristics which same function as a dc-dc boost converter [2,3]. A simple CL filter is used for CSI for harmonic elimination.

Sinusoidal pulse width modulation (SPWM) is the common modulation technique for both VSI and CSI. SPWM for CSI can be extended from SPWM VSI, yet it needs an additional gating pattern generator to convert the gating pattern develop for VSI to the gating pattern that can be used by CSI $[1,11]$. 


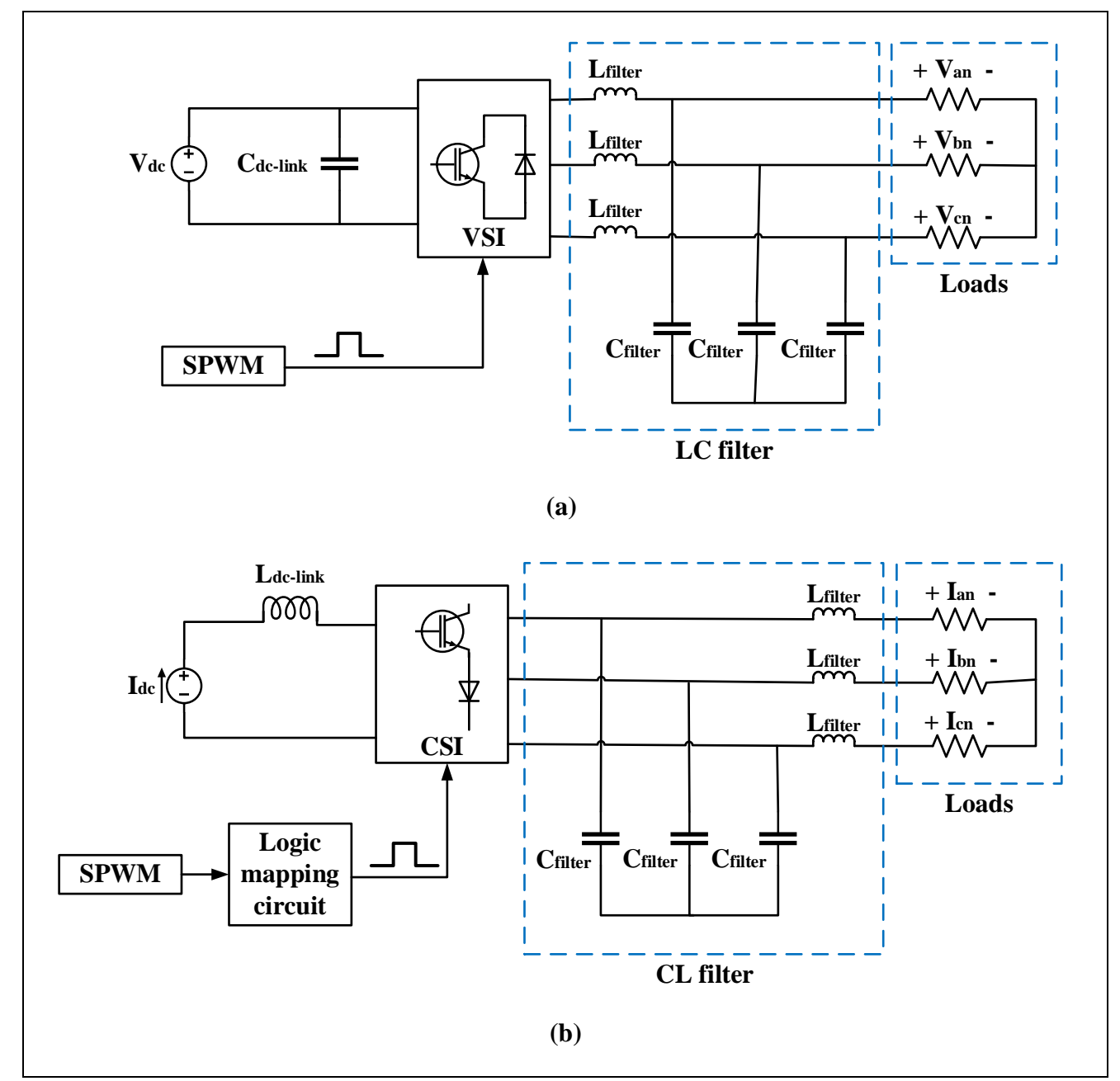

Figure 1. Basic topologies of (a) voltage source inverter (b) current source inverter.

\subsection{Power Circuit Designation}

(a) Voltage source inverter

For an ideal SPWM VSI with modulation index, $m_{a}$ is 1 , the dc voltage magnitude is expressed as (1) [1]:

$$
V_{d c}=2 V_{\varnothing, \text { peak }}
$$

From (1), a theoretical minimum dc input voltage of $651 \mathrm{~V}$ is needed to achieve Malaysia's grid voltage which is $230 \mathrm{~V}_{\text {rms }}$. Accounting for the switching device losses and system power losses, $700 \mathrm{~V}$ dc input voltage is selected as dc input voltage.

(b) Current source inverter

For an ideal SPWM CSI with modulation index, $m_{a}$ is 1 , the DC current magnitude is expressed as (2) [1]:

$$
I_{d c}=\frac{2}{\sqrt{3}} I_{\varnothing, \text { peak }}
$$

Since the system output rated power is $2 \mathrm{~kW}$ with a grid voltage of $230 \mathrm{~V}_{r m s}$, a theoretical minimum dc input current 4.099A is needed. Similar to the VSI, CSI also has switching and system losses, thus $5 \mathrm{~A}$ dc input current is selected.

\subsection{Modulation Index, $\boldsymbol{m}_{a}$}

Modulation index is defined as the ratio of amplitudes of reference and carrier signals shown as (3) [9].

$$
m_{a}=\frac{V_{m, \text { reference }}}{V_{m, \text { carrier }}}=\frac{V_{m, \text { sine }}}{V_{m, \text { tri }}}
$$

By using SPWM modulation techniques, the output of VSI and CSI are dependent on $m_{a}$. For VSI, the amplitude of the phase voltage and line-to-line voltage are according to (4) and (5) [1]:

$$
\begin{gathered}
V_{\varnothing, \text { peak }}=m_{a}\left(\frac{V_{d c}}{2}\right), 1 \leq m_{a} \\
V_{L-L, \text { peak }}=m_{a} \sqrt{3}\left(\frac{V_{d c}}{2}\right), 0 \leq m_{a} \leq 1
\end{gathered}
$$

Next, for CSI, the amplitude of phase current is according to (6) [1]: 


$$
I_{\varnothing, \text { peak }}=I_{L-L, \text { peak }}=m_{a} \sqrt{3}\left(\frac{I_{d c}}{2}\right), 0 \leq m_{a} \leq 1
$$

\subsection{Switching Frequency, $f_{s w}$}

Frequency modulation ratio, $m_{f}$ is defined as the ratio of the frequencies of carrier and reference signals shown as (7) [9]:

$$
m_{f}=\frac{f_{\text {carrier }}}{f_{\text {reference }}}=\frac{f_{\text {tri }}}{f_{\text {sine }}}
$$

There are some high harmonics with high magnitude always exist and around the $m_{f}$. Based on (7), switching frequency increase will increase $m_{f}$, thus increasing the frequency at which the harmonics occur. In [9], it states that a normalized switching frequency should be an odd multiple of three so that the ac line voltage output does not contain any harmonic at the frequency of odd multiple of three.

Table 1. SPWM VSI and CSI system parameters

\begin{tabular}{ccccc}
\hline \multirow{2}{*}{ Characteristics } & \multicolumn{3}{c}{ VSI } & \multicolumn{2}{c}{ CSI } \\
\cline { 2 - 5 } & Test I & Test II & Test I & Test II \\
\hline $\begin{array}{c}\text { DC link } \\
\text { voltage, } \mathrm{V}_{\mathrm{dc}}\end{array}$ & $700 \mathrm{~V}$ & $700 \mathrm{~V}$ & - & - \\
\hline $\begin{array}{c}\text { DC link } \\
\text { current, } \mathrm{I}_{\mathrm{dc}}\end{array}$ & - & - & $5 \mathrm{~A}$ & $5 \mathrm{~A}$ \\
\hline $\begin{array}{c}\text { Grid voltage, } \\
\mathrm{V}_{\text {grid }}\end{array}$ & $230 \mathrm{~V}_{\text {rms }}$ & $230 \mathrm{~V}_{\text {rms }}$ & $230 \mathrm{~V}_{\text {rms }}$ & $230 \mathrm{~V}_{\text {rms }}$ \\
\hline $\begin{array}{c}\text { Rated power, } \\
\mathrm{P}_{\text {rated }}\end{array}$ & $2 \mathrm{~kW}$ & $2 \mathrm{~kW}$ & $2 \mathrm{~kW}$ & $2 \mathrm{~kW}$ \\
\hline $\begin{array}{c}\text { Fundamental } \\
\text { frequency, } f_{o}\end{array}$ & $50 \mathrm{~Hz}$ & $50 \mathrm{~Hz}$ & $50 \mathrm{~Hz}$ & $50 \mathrm{~Hz}$ \\
\hline $\begin{array}{c}\text { Modulation } \\
\text { index, } m_{a}\end{array}$ & $0.05-1.0$ & 0.9 & $0.05-1.0$ & 0.8 \\
\hline $\begin{array}{c}\text { Switching } \\
\text { frequency, } f_{s w}\end{array}$ & $2 \mathrm{kHz}$ & $500 \mathrm{H}-10 \mathrm{kHz}$ & $2 \mathrm{kHz}$ & $500-10 \mathrm{kHz}$ \\
\hline \begin{tabular}{c} 
Load, $\mathrm{R}$ \\
\hline
\end{tabular} & $100 \Omega$ & $100 \Omega$ & $100 \Omega$ & $100 \Omega$ \\
\hline
\end{tabular}

\section{Comparison Analysis of VSI and CSI}

The parameters used for VSI and CSI in this comparative analysis are shown in table 1 . The performance of both inverters is determined in term of fundamental output and total harmonic distortion (THD).

\subsection{Test I: Modulation Index, $m_{a}$}

Test I is conducted to identify an optimum modulation index to be used in the proceeding analysis with consideration of good fundamental output value and low THD. In this test, the modulation index is varied from 0.05 to 1 while the switching frequency is fixed at $2 \mathrm{kHz}$. Figure 2 presents the fundamental output and THD of VSI and CSI respectively with modulation index, $m_{a}$ varying from 0.05 to 1 . Figure 2(a), (b) and (c) present the phase voltage, phase current and the line-to-line voltage simulation results respectively. From figure 2 it is found out that the fundamental output of both inverters is increased directly proportional to $m_{a}$ while the THD is decreased exponentially to $m_{a}$.

CSI has presented an interesting feature of boosting capability of its dc-link inductor in figure 2. In order to achieve Malaysia's grid voltage which is $230 \mathrm{~V}_{r m s} / 400 \mathrm{~V}_{r m s}$, VSI required to use $0.9 m_{a}$ while CSI can use $0.8 m_{a}$. CSI can achieve a higher fundamental output by using lower $m_{a}$ compared to VSI. Table 2 shows the boosting capability of CSI compared to VSI. CSI able to boost its fundamental output to about $6 \%-27 \%$ within the modulation index range of 0.05 to 1 . This indicates that a dc-dc boost converter is unnecessary for CSI, thus the complexity of CSI power system is simpler.

Furthermore, the THD result of VSI and CSI shows that both inverters have approximately the same THD under same modulation index by using a fixed $2 \mathrm{kHz}$ switching frequency. It indicates that THD of both inverters is not much affected by the modulation index. 

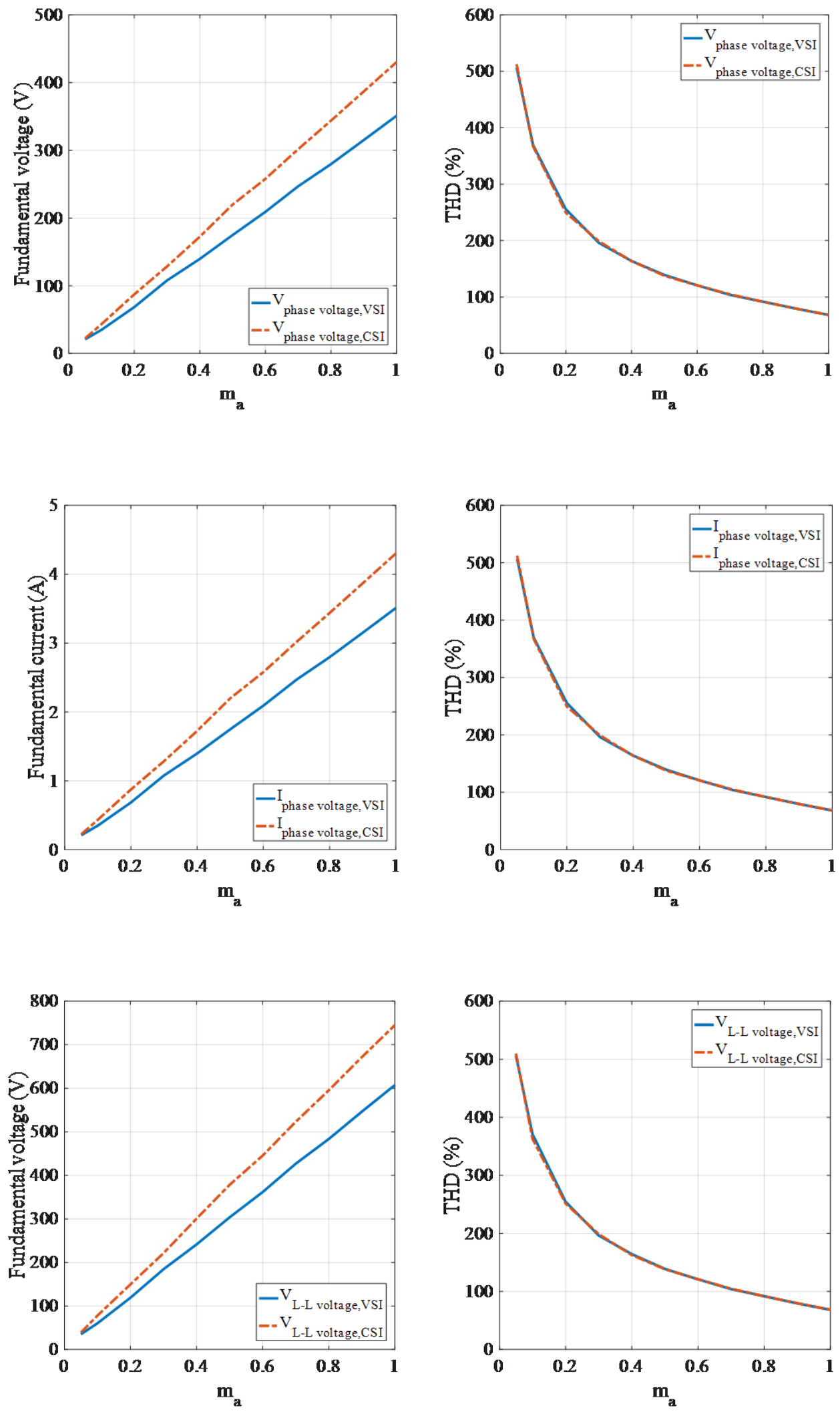

Figure 2. Fundamental voltage and THD for SPWM VSI and CSI under varying $m_{a}$ (a) phase voltage (b) phase current (c) line-to-line voltage. 
Table 2. Boosting capability of SPWM CSI

\begin{tabular}{cccc}
\hline \multirow{2}{*}{ ma } & \multicolumn{3}{c}{ Vø, peak $(\mathrm{V})$} \\
\cline { 2 - 4 } & VSI & CSI & Boost capability (\%) \\
\hline 0.05 & 21.0 & 22.33 & 6.587 \\
\hline 0.10 & 35.0 & 43.42 & 24.199 \\
\hline 0.20 & 68.6 & 87.40 & 27.424 \\
\hline 0.30 & 107.9 & 128.60 & 19.184 \\
\hline 0.40 & 139.7 & 172.50 & 23.479 \\
\hline 0.50 & 174.9 & 219.90 & 25.729 \\
\hline 0.60 & 209.2 & 257.90 & 23.279 \\
\hline 0.70 & 246.9 & 301.70 & 22.195 \\
\hline 0.80 & 279.6 & 343.80 & 22.961 \\
\hline 0.90 & 315.1 & 386.90 & 22.786 \\
\hline 1.00 & 351.0 & 430.20 & 22.564 \\
\hline
\end{tabular}

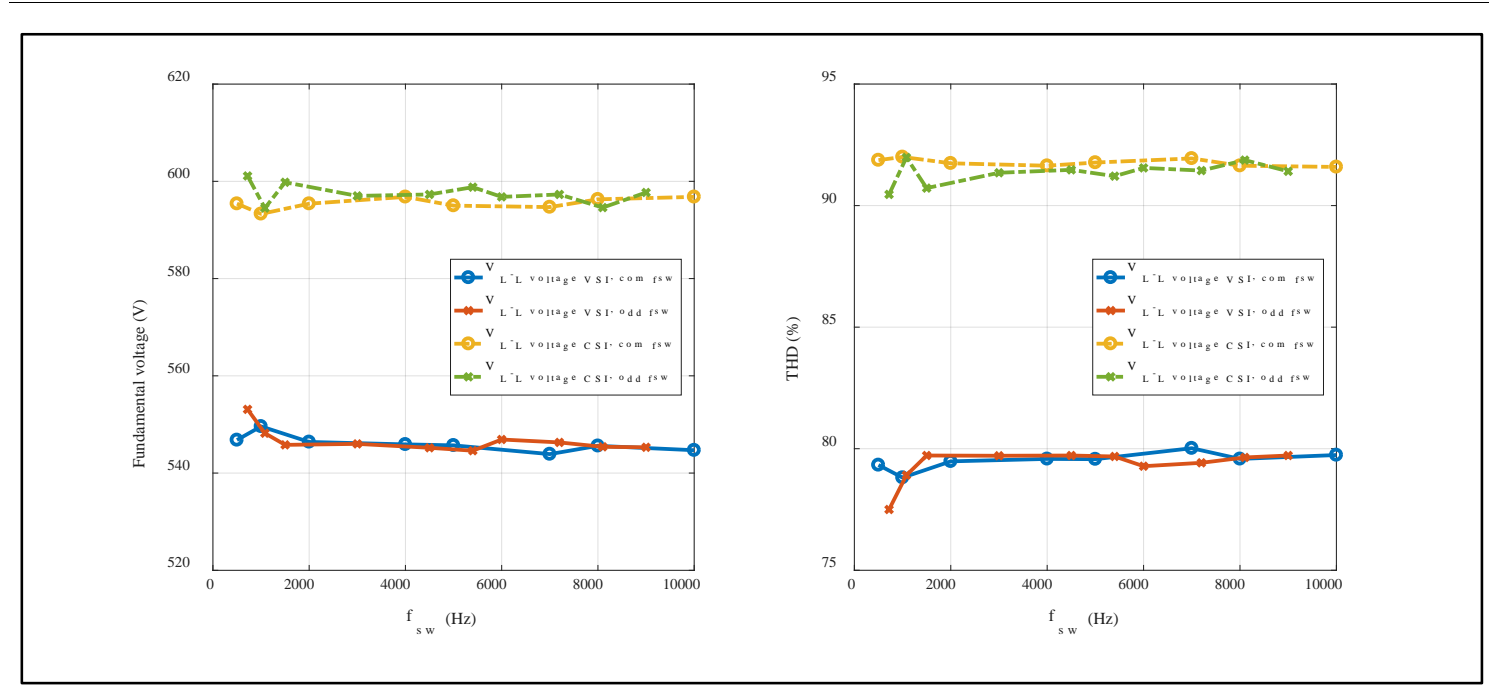

Figure 3. Fundamental voltage and THD of line-to-line voltage for SPWM VSI and CSI under varying $f_{s w}$

\subsection{Test II: Switching frequency, $f_{s w}$}

Test II is a varying switching frequency test by using a fixed modulation index, which is $0.9 m_{a}$ for VSI and $0.8 m_{a}$ for CSI. Figure 3 has presented the simulation result of VSI and CSI under varying switching frequency by using a group of common switching frequency and a group of odd multiple of three switching frequency. The phase voltage and phase current have the same trending with the line-to-line voltage.

In figure 3 , it indicates that the increase of switching frequency does not have much effect on fundamental output and THD for SPWM VSI and CSI. From overall result, the line-to-line voltage has a better performance by using the switching frequency of odd multiple of three which provides higher fundamental output and lower THD. Furthermore, CSI always has a higher fundamental output and THD compared to VSI. This indicates that CSI can provide better fundamental output, but it always has higher THD compared to VSI.

Figure 4 presented the line-to-line voltage FFT analysis of VSI at $720 \mathrm{~Hz}$ and $3000 \mathrm{~Hz}$. CSI line-to-line voltage FFT analysis also has the same trending. In figure 4 , it shows that there are some high magnitude harmonics exist around the $m_{f}$. This also proves that equation (7) which states that when the switching frequency increases, the frequency modulation, $m_{f}$ increases thus increasing the frequency at which the harmonics occur. 


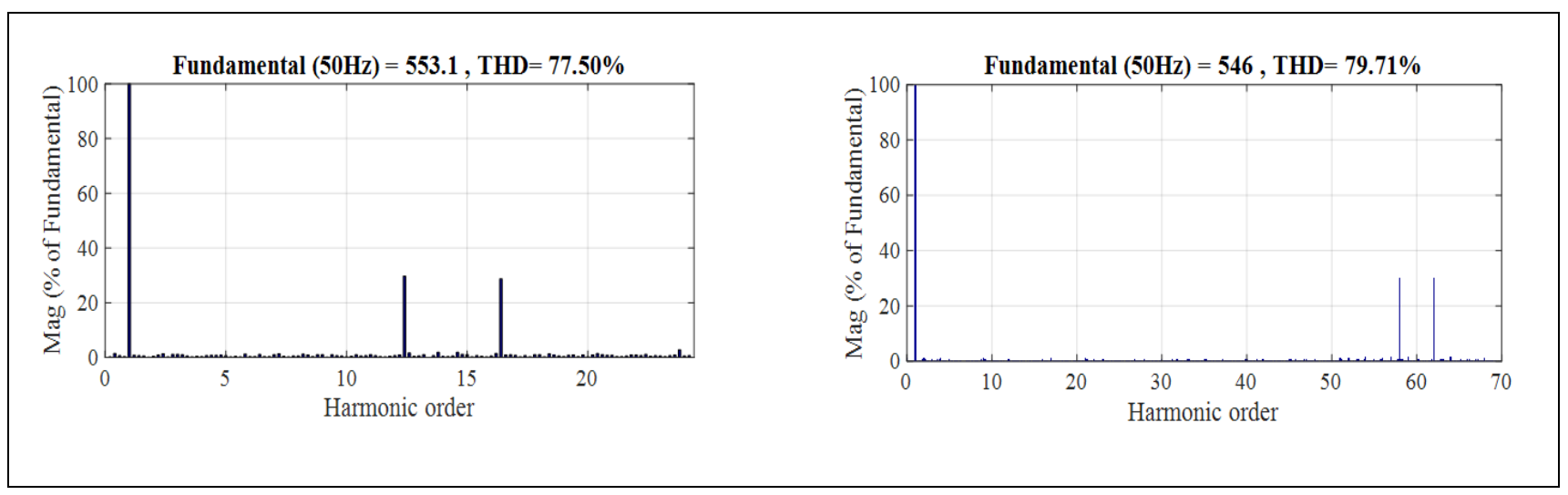

Figure 4. Line-to-line voltage FFT analysis of VSI at (a) $720 \mathrm{~Hz}$ (b) $3000 \mathrm{~Hz}$

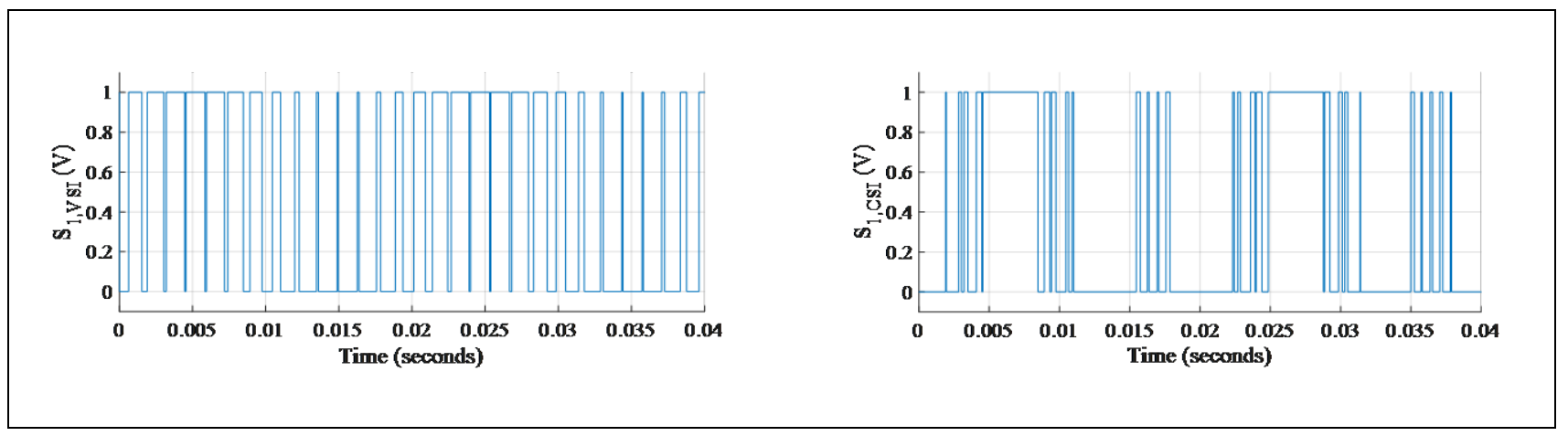

Figure 5. Upper switching signal, $S_{1}$ for VSI and CSI by using $720 \mathrm{~Hz}$ as switching frequency

\subsection{Duality of VSI and CSI}

Based on Test I, $m_{a}=0.9$ for VSI and $m_{a}=0.8$ for CSI are needed to produce an output approximately to Malaysia's grid voltage. A normalized switching frequency which is $3000 \mathrm{~Hz}$ is selected since it provides an optimized fundamental output and THD for VSI and CSI as shown in figure 3.

Since VSI and CSI both using the SPWM modulation technique to operate, the switching pattern of upper switching signal, $S_{1}$ for VSI and CSI are compared in figure 5 by using $720 \mathrm{~Hz}$ as switching frequency. In figure 5 , it shows that VSI has 30 pulses turned on while CSI has 27 pulses turned on during 2 cycles period. With this assumption, it can predict that CSI may have a lower switching loss compared to VSI.
The output waveform of SPWM VSI and CSI using the selected $m_{a}$ and $f_{s w}$ from Test I and Test II are shown in figure 6. Some CSI output waveform patterns are identical with VSI output waveform. In figure, the CSI phase voltage and current waveform are identical to VSI line-to-line voltage waveform. Furthermore, the CSI line-to-line voltage waveform is identical to VSI phase voltage and current waveform. This established the duality relationship between VSI and CSI.

However, even some waveform pattern of VSI and CSI are identical, the output of VSI and CSI are different. In figure 6 , the overall outputs of CSI which from phase voltage, phase current and line-to-line voltage are higher than VSI. Furthermore, from THD simulation result which shows in figure 3, CSI always has a higher THD compared to VSI. 


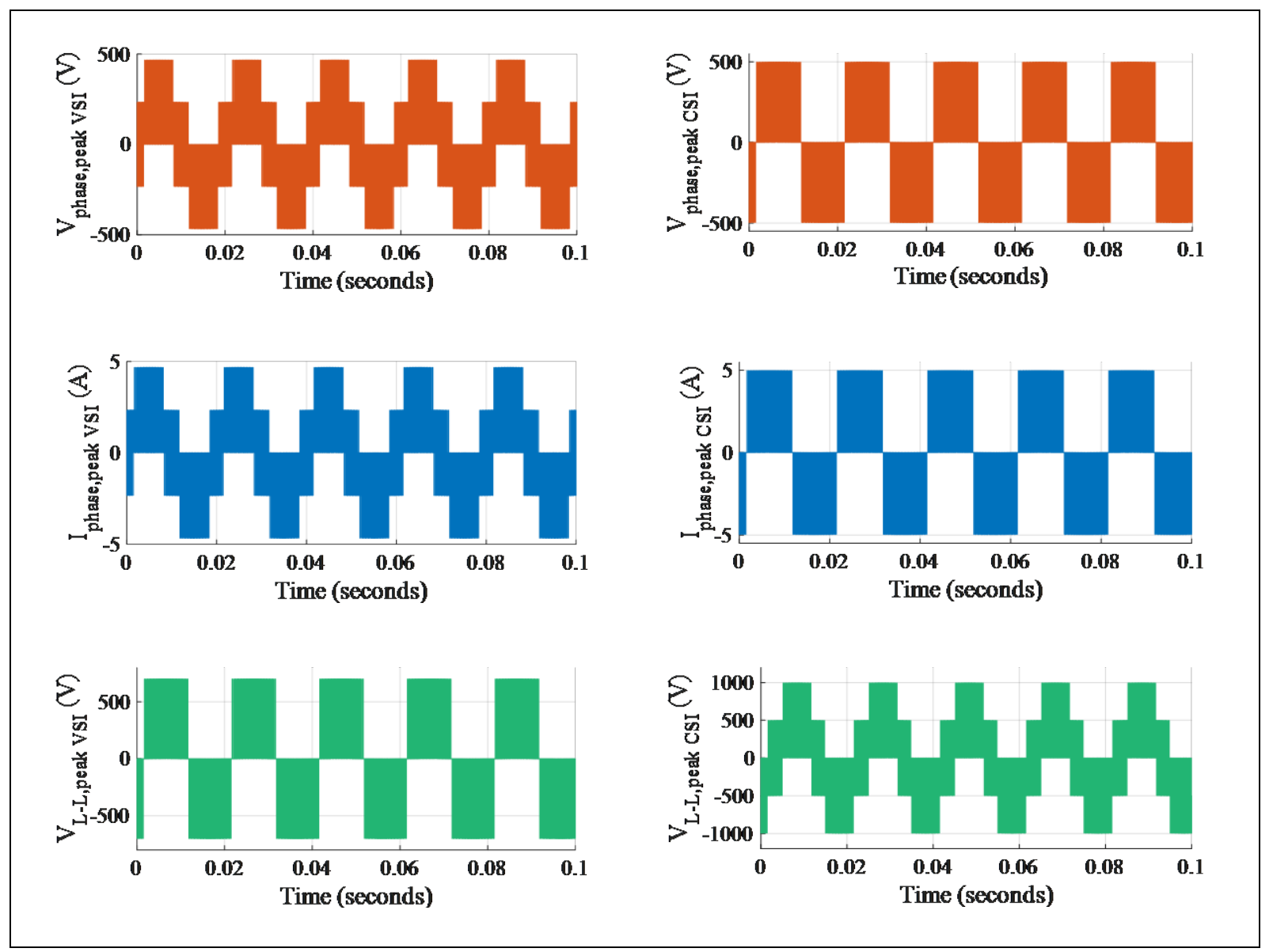

Figure 6. Output waveform of VSI ( $\left.m_{a}=0.9\right)$ and CSI ( $\left.m_{a}=0.8\right)$ by using $3000 \mathrm{~Hz}$ as switching frequency: (a) phase voltage (b)phase current (c) line-to-line voltage

As a summary, VSI and CSI have some duality relationship in term of circuit design, modulation techniques used and output waveform pattern. However, VSI and CSI both have different features in detail which provide a significant effect on output and advantages. Thus, a selection of suitable inverter topology is important in order to fulfil industrial usage.

\section{Conclusion}

This paper compares the voltage source inverter (VSI) and current source inverter (CSI) by using sinusoidal pulse width modulation (SPWM) techniques. A comparative analysis of VSI and CSI can be concluded as:

- Both VSI and CSI output efficiency is depending on the modulation index, $m_{a}$. The efficiency of both inverters increases with increasing $m_{a}$.

- $\quad$ CSI has implicit voltage boosting ability due to its dc-link inductor. It can boost up to $6 \%-27 \%$ within linear modulation index range.

- Switching frequency, $f_{s w}$ does not influence on the efficiency of the inverters. However, a normalized switching frequency should be in an odd multiple of three.
- $\quad$ CSI can provide better performance on fundamental output, but it has higher THD compared to VSI.

- $\quad$ By using the same modulation techniques, the output waveform of VSI and CSI show a duality relationship between the inverters.

\section{Acknowledgements}

The authors would like to acknowledge Centre of Excellent for Renewable Energy (CERE), Universiti Malaysia Perlis for the financial support of this research work.

\section{REFERENCES}

[1] P. D. Muhammad H. Rashid, Power Electronics Handbook, 4th ed. Joe Hayton, 2018.

[2] S. A. Azmi, K. H. Ahmed, S. J. Finney, and B. W. Williams, "Comparative analysis between voltage and current source inverters in grid-connected application," in IET Conference on Renewable Power Generation (RPG 2011), 2011, pp. 16. 
[3] M. Mohr and F. W. Fuchs, "Comparison of three phase current source inverters and voltage source inverters linked with DC to DC boost converters for fuel cell generation systems," in 2005 European Conference on Power Electronics and Applications, 2005, pp. 1-10.

[4] J. M. Aaron VanderMeulen, "Current source inverter vs. Voltage source inverter topology," White Pap. WP020001EN, no. June, pp. 1-8, 2014.

[5] V. Delli Colli, P. Cancelliere, F. Marignetti, and R. Di Stefano, "Influence of voltage and current source inverters on low-power induction motors," IEE Proc. - Electr. Power Appl., vol. 152, no. 5, p. 1311, 2005.

[6] Y. Suh, J. K. Steinke, and P. K. Steimer, "Efficiency Comparison of Voltage-Source and Current-Source Drive Systems for Medium-Voltage Applications," in IEEE Transactions on Industrial Electronics, 2007, vol. 54, no. 5, pp. 2521-2531.

[7] E. P. Wiechmann, P. Aqueveque, R. Burgos, and J. Rodriguez, "On the Efficiency of Voltage Source and Current Source Inverters for High-Power Drives,” in IEEE Transactions on Industrial Electronics, 2008, vol. 55, no. 4, pp. 1771-1782.

[8] P. A. Dahono, T. Kataoka, and Y. Sato, "Dual relationships between voltage-source and current-source three-phase inverters and its applications," in Proceedings of Second International Conference on Power Electronics and Drive Systems, 1997, vol. 2, pp. 559-565.

[9] Daniel W.Hart, Power Electronics. Americans, New York: McGraw-Hill Companies, 2011.

[10] K. B. Nagasai and T. R. Jyothsna, "Harmonic Analysis and Application of PWM Techniques for Three Phase Inverter," Int. Res. J. Eng. Technol., pp. 2395-56, 2016.

[11] S. A. Azmi, G. P. Adam and B. Williams, "New direct regular-sampled pulse-width modulation applicable for grid and islanding operation of current source inverters," IET Power Electron., vol. 7, no. 1, pp. 220-236, Jan. 2014.

[12] Ismail B., Hassan S I S., Ismail R C, Azmi A and Arshad, "Elimination of lower order harmonics in multilevel cascaded inverters with equal DC sources using PSO," International Review on Modelling and Simulation (IREMOS), 7(4), 554-560, 2014.

[13] Ismail B, Arshad M H and Sengodan T, "FPGA based implementation of selective harmonic elimination PWM for cascade inverter," International Review on Modelling and Simulations(IREMOS), Vol. 5.N.5, pp. 1919-1926, 2012. 